\title{
THE EU APPORTIONMENT FORMULA: INSIGHTS FROM A BUSINESS CASE
}

\author{
Annelies Roggeman ${ }^{1}$, Isabelle Verleyen ${ }^{2}$, \\ Philippe Van Cauwenberge ${ }^{3}$, Carine Coppens ${ }^{4}$ \\ ${ }^{1,2,4}$ Faculty of Business and Information Management, University College Ghent, \\ Valentin Vaerwyckweg 1, B-9000 Ghent, Belgium \\ ${ }^{3}$ Department of Accountancy and Corporate Finance, Ghent University, \\ Kuiperskaai 55E, B-9000 Ghent, Belgium \\ E-mails: 1annelies.roggeman@hogent.be; \\ ${ }^{2}$ isabelle.verleyen@hogent.be (corresponding author); \\ 3philippe.vancauwenberge@ugent.be; ${ }^{4}$ carine.coppens@hogent.be
}

Received 21 March 2011; accepted 25 October 2011

\begin{abstract}
In this paper we use firm level data from a listed multinational to investigate how several designs for the Common Consolidated Corporate Tax Base (CCCTB) formula could affect the allocation of the consolidated tax base. The design is relevant in the light of member states' concern for protecting their tax revenues, as well as for the multinational companies' tax minimizing possibilities. Moreover, it plays an important role in achieving an efficient and simple tax system. Simulating different apportionment formulas, the results show that including more factors and using more equal weights distributes the common tax base more equally, which could reduce the incentive to shift factors from high to low tax countries. The results also indicate that simplifying the factor definitions, leads to rather minor changes in the allocation. Using unpublished data, this study allows to investigate the consequences of different formulas in detail, which contributes to the current discussion on corporate tax harmonization in the EU.
\end{abstract}

Keywords: CCCTB, corporate tax, European Union, apportionment formula.

Reference to this paper should be made as follows: Roggeman, A.; Verleyen, I.; Van Cauwenberge, P.; Coppens, C. 2013. The EU apportionment formula: insights from a business case, Journal of Business Economics and Management 14(2): 235-251.

JEL classification: F23, F59, H25, H32, H87.

\section{Introduction}

In 2004, the European Union (EU) welcomed ten countries of Central and Eastern Europe. Bulgaria and Romania joined the EU in 2007, which brought the total number of member states (MS) to twenty-seven. Notwithstanding this big achievement, the enlargement of the EU makes some policy problems even more pressing. One such problem relates to the several tax obstacles that are currently harming the international competitiveness of multinationals. Multinationals, for example, face high compliance 
costs because of the different tax systems across the twenty-seven MS. Other tax obstacles concern the limitation on cross-border loss relief and the problems with transfer pricing for intra group transactions (EC 2001a).

To remove the underlying causes of all tax obstacles, the EU wants to introduce a Common Consolidated Corporate Tax Base (CCCTB). This new tax system should contribute to the Europe 2020 growth strategy that was established by the European Commission in March 2010 (EC 2010). In particular, it has the intention to increase the efficiency, effectiveness, simplicity and transparency within the European company tax system (EC 2001a; EC 2001b; EC 2006a). The tax liability of a company belonging to a CCCTB group would be determined by applying four distinct steps. Firstly, each group member has to calculate its taxable profit according to the same set of rules. Secondly, the individual tax bases are summed up to the consolidated tax base. Thirdly, the consolidated tax base is allocated to the different group members by means of an apportionment formula (AF). Finally, each MS has the right to apply its own tax rate to the specific share of the overall tax base (Schön et al. 2008).

In this paper we use financial data from a listed multinational in order to illustrate how several designs of the AF could affect the allocation of the consolidated tax base among different group entities. The design of the formula plays an important role in achieving an efficient and simple tax system (Spengel, Wendt 2007). Previous studies investigated the macro-economic effects of introducing an AF in Europe. Devereux and Loretz (2008) showed that the overall tax revenue would be likely to decline by $2.5 \%$ if companies could choose whether or not to participate to CCCTB. Runkel and Schjelderup (2011) found that central authorities would use apportionment weights as a corrective devise in order to reduce tax distortions. The simulation results of Bettendorf et al. (2010) showed that an AF does not weaken incentives for tax competition. Important to mention is that the results of these studies are highly dependent on the design of the formula. A drawback of the existing literature is the lack of confidential firm level data. However, using such data makes it possible to understand the complexity and relative newness of the European AF. In this research, the availability of unpublished data offered the opportunity to study the factors in detail. For example, we were able to use the sales by destination factor whereas previous research always relied on the sales by origin factor.

The simulation results show that including more factors and using more equal weights distributes the common tax base more equally. Moreover, this could reduce the incentive to shift factors from high to low tax countries, which improves the efficiency of the new tax system. The results also indicate that simplifying the factor definitions leads to rather minor changes in the allocation.

The paper is organized as follows. Section 2 gives an overview of the principles of the apportionment formula. The development of the research questions is presented in section 3. The data and methodology are given in section 4. Section 5 presents the results and discussions. Section 6 concludes. 


\section{Principles of the sharing mechanism}

The Commission's working paper 'The mechanism for sharing the CCCTB' (EC 2006b) mentions three ways to share the consolidated tax base: one macro-based approach, and two firm-specific approaches namely, the Value Added Key (VA) and the Apportionment Formula (AF). The macro-based approach implies that the common tax base of any CCCTB group should be allocated to the member states with reference to factors aggregated at the national level (GDP, VAT bases,...). The Value Added Key, designed for the purpose of apportioning a common tax base, should be calculated as an incometype measure that accounts for depreciation allowances (Agundez-Garcia 2006). The AF could be defined as 'a method for determining the corporate tax base of a single company or group of associated companies attributable to a member state (MS) by reference to a formula that assigns a proportionate share of the company's or associated companies' corporate tax base to the state by reference to a factor or factors that reflect (or are deemed to reflect) the underlying income-producing activities within the state' (Hellerstein 2005).

The 'ideal' sharing approach has the intention to be simple, difficult to manipulate, fair and equitable (EC 2007b; Agundez-Garcia 2006). Moreover, it should not lead to undesirable effects in terms of tax competition. It turns out all three systems have advantages as well as drawbacks and therefore it is not appropriate to state that one method is in all respects better than the others (EC 2006b). The greatest disadvantage of the macro-based approach is that it may decouple an individual firm's tax payment to a member country from its real economic activity in that country. With respect to the VA, the main drawback is that it reintroduces the need to value all intra-EU group transactions ('transfer pricing') as a result of the strong profit-shifting incentives. The AF is nowadays seen as the preferred approach by the Commission because of the numerous disadvantages of the first two methods (Agundez-Garcia 2006).

The system of apportionment formula is well known in the US states and the Canadian provinces. Introduced in 1967, the 'Massachusetts' formula became widely used by the US states for some considerable time. This formula includes equally-weighted property, payroll and gross receipts factors. Since 1978 until now, about two thirds of the states have deviated from the Massachusetts formula. The most frequent deviation is to double weight the sales factor in order to attain a balance in the apportionment of income between producing (assets and payroll) and marketing states (gross receipts) (Anand, Sansing 2000). Canada introduced a single-factor formula including a destination based gross receipts and added a payroll factor to the formula later on. In contrast to Europe, each American and Canadian state has the privilege to define its own design of the apportionment formula. For that reason, we cannot compare our results with the results for these contexts (Hey 2008; Weiner 2005).

Based on the Massachusetts formula, the Commission suggests a multiple-factor formula taking into account both the supply and demand side on the generation of companies' income. The supply side is traditionally represented by the production factors labour and capital, whilst the demand side is represented by sales by destination. The labour factor will be measured both by means of payroll and number of employees. 
The Commission suggests to apportion a share of the common tax base to a company $i$ of a given group as follows (EC 2007b):

$$
\mathrm{TB}_{i}=\mathrm{CTB}\left[\alpha \frac{S_{i}}{\sum_{i=1}^{n} S_{i}}+\beta\left[\lambda \frac{P_{i}}{\sum_{i=1}^{n} P_{i}}+\delta \frac{E_{i}}{\sum_{i=1}^{n} E_{i}}\right]+\gamma \frac{A i}{\sum_{i=1}^{n} A_{i}}\right],
$$

CTB stands for the common tax base. Subscript $i$ denotes company $i$ from a group of $n$ companies. A stands for fixed tangible assets, $\mathrm{S}$ is sales by destination, $\mathrm{P}$ represents employee compensation while $\mathrm{E}$ stands for the number of employees. $\alpha, \beta$ and $\gamma$ are the weights of the three factors such that $\alpha+\beta+\gamma=1$. The weights of the two labour factors employee compensation and number of employees are represented by $\lambda$ and $\delta$ respectively and $\lambda+\delta=1$.

\subsection{Labour}

The labour factor is meant to reflect the contribution of labour as a production factor in the generation of corporate income. According to the recommendations of the CCCTB $\mathrm{WG}$, the labour factor should combine the payroll factor (cost of employees) and the number of employees factor in order to restrict the shortcomings of the two factors separately. With regard to the qualifying work force, it is suggested that also interim and temporary employment should be included. The payroll costs are considered as the remunerations that qualify as a deductible expense for the purpose of calculating the tax base, including fringe benefits, social contributions and stock options. With respect to the location of labour, it is put forward to look at the place where the employees provide their services (EC 2007b).

\subsection{Assets}

Although the share of intangibles, financials and currents assets can be considerably high, the Commission suggests that only fixed tangible assets should be included. The Commission argues that intangible, financial and current assets (inventory) are very mobile and could be used as a tax-planning tool to shift part of the factor from one jurisdiction to another. The year end's tax written down value could be taken into account to calculate the asset factor. An alternative could be to take the average value of the tax written down value at the beginning and ending of the tax year in order to reflect the fluctuation of assets during the tax year. With respect to the location of fixed assets, it is suggested to attribute the asset to the entity which is effectively using the assets (EC 2007b).

\subsection{Sales}

The most controversial factor during the discussions in the WG was the sales factor. Next to the discussion whether or not to include a sales factor, a discussion is going on about sales by origin versus sales by destination. The former takes into account the place from which the goods are shipped while the latter takes into account the place in which the goods are shipped. The Commission suggests a sales by destination factor 
because such a factor is less easy to manipulate and would limit the overall impact on tax competition in the EU due to its 'immobility'. It is proposed that only proceeds of sales of goods and provision of services should be covered. With respect to the value of sales, the figure taken into account should be the one considered for the purpose of calculating the tax base. Moreover, it is suggested to attribute sales to the entity which is located in the member state where the final place of physical delivery is situated. The problem of nowhere sales arises when the group does not have a permanent establishment or subsidiary in the destination state of sales or if the destination state is a nonEuropean country. There are several ways to deal with these nowhere sales. The first option is to leave these sales out of consideration. The second option includes a pure throw back rule, i.e. the nowhere sales are thrown back to the state of origin. Finally, a spread throw back rule could be applied. In this case these sales are thrown back to all group entities in proportion to the other formula factors. The Commission suggests using this spread throw back rule (EC 2007b).

\section{Development of research questions}

Studies in Canada and the US show that lack of uniformity can result in double taxation or under taxation (Weiner 2005). Moreover, a non-uniform formula does not maximize the social welfare of the member states (Anand, Sansing 2000). These problems would be even worse in Europe because of the higher differences in levels of corporate tax rates (Hey 2008). Therefore, unlike the US, European member states should not be allowed to add or eliminate factors, to change definitions or to apply different weights (EC 2007b). In spite of the conviction to use a uniform formula, a discussion is going on about the actual number of allocation factors to be included, the weights applied to them and their definitions.

\subsection{Varying the number of factors}

The number of factors included will influence the tax planning opportunities for the group. If the formula includes only one factor there can be a strong incentive to relocate this factor to a low tax country in order to decrease the overall EU-tax rate. Important to mention is that the immobility of the factors could hamper the possibility to relocate these factors. This is one of the reasons the Commission proposes a multiple factor formula including the rather immobile combined labour factor (number of employees and costs of employees), the sales by destination factor and the fixed tangible assets factor, instead of rather mobile factors such as inventory and intangible assets. By using a multiple factor formula the reallocation incentive is reduced, i.e. the relocation of one unit of these factors would shift less than one unit of the tax base (EC 2007b). Bearing in mind the above literature, we want to illustrate the formula's sensitivity to the number of factors included. More specifically, we investigate the following questions:

To what extent do the allocation effects differ when assuming equal weights and varying the number of factors?

What is the effect on the group's incentive to relocate one or more apportionment factors? 


\subsection{Varying the factor weights}

Besides the number of factors included, the weights applied to the factors will also influence tax planning opportunities. Using a formula with more than one factor requires all factors to be weighted by a fraction so that the sum of these weights equals one. Ignoring this condition can lead to under-taxation or double taxation (EC 2007a).

We can distinguish different methods of assigning factor weights. First, a straightforward way is to weight each factor equally. The Massachusetts formula, including the equally weighted factors property, payroll and gross receipts, became widely used by the US. Since its introduction, about two thirds of the states have deviated from the Massachusetts formula. Nowadays, the most frequent deviation is to double weight the sales factor in order to attain a balance in the apportionment of income between producing (assets and payroll) and marketing states (gross receipts) (Anand, Sansing 2000). This second way of assigning factor weights can also be illustrated by the Canadian provinces using a two-factor payroll and gross revenue formula that is equally weighted. In the light of the European proposal, a balance between supply and demand side could be realised by weighting payroll and assets by one quarter each and sales by one half. On the contrary, if the supply or demand approach would be favoured, greater weight could be put on the supply and demand factors respectively (Weiner 2005; Agundez-Garcia 2006). Finally, specific factor weights may be estimated using econometric analysis. In particular, factors may be weighted according to the specific contribution each factor makes to the overall profits (Agundez-Garcia 2006; Weiner 2005). Keeping in mind the above literature, we want to illustrate the formula's sensitivity to the weights applied to the factors. More specifically, we examine the following questions:

To what extent do the allocation effects differ when assuming three factors and varying the weights applied to these factors?

What is the effect on the group's incentive to relocate one or more apportionment factors?

\subsection{Varying the factor definitions}

Another important issue is the applicability of the formula. The Commission suggests to apply several tax corrections to the book values of fixed tangible assets and labour. Moreover, the Commission wants to use a spread throw back rule in case of nowhere sales. Instead of using the Commission's definitions, one could opt for more easily defined factors. If using more easily defined factors results in minor changes to the allocation of the common tax base, the higher compliance costs the proposed definitions bring along are more difficult to justify. On the contrary, the higher compliance cost could possibly be justified if using more easily defined factors results to major changes in the allocation. In this research we leave the size of the compliance costs out of consideration and focus on the possible changes in allocation effects when using different factor definitions. We investigate the following question:

To what extent do the allocation effects differ when using simplified factor definitions instead of the more complex factor definitions as proposed by the Commission? 


\section{Data collection and methodology}

\subsection{Data collection}

To assess the effects of several designs for the AF, we use data of 2007 from a listed multinational active in the clothing manufacturing sector. All core activities of the multinational are conducted at the headquarters in Belgium. The structure of the company during the financial year 2007 can be given upon request. We name each entity after the country where it is located. To form the CCCTB group we consider the criteria as proposed by the technical outlines. The qualifying subsidiaries are mentioned in Table 1 .

Table 1. Descriptive statistics for the CCCTB entities

\begin{tabular}{lccccc}
\hline & Assets (A) & Employees ( E) & Payroll (P) & Sales (S) & Taxable profit \\
\hline Belgium & $12,162,944$ & 431 & $15,505,091$ & $44,682,307$ & $36,951,548$ \\
\hline Italy & 327 & 1 & 165,521 & $1,783,780$ & 87,685 \\
\hline Great-Britain & 0 & 3 & 242,297 & $8,008,093$ & 10,117 \\
\hline Netherlands & 59,513 & 6 & 375,243 & $16,892,369$ & 616,511 \\
\hline Luxembourg & 0 & 0 & 0 & 718,302 & 108,891 \\
\hline Hungary & $1,856,927$ & 368 & $2,620,295$ & $3,726,075$ & 990,480 \\
\hline Finland & 3,225 & 2 & 95,040 & $2,831,084$ & 139,277 \\
\hline France1 & 3,476 & 15 & 946,976 & $5,288,804$ & $-27,296$ \\
\hline Germany1 & 0 & 0 & 0 & 0 & 3,422 \\
\hline Germany2 & 9,194 & 15 & $1,111,216$ & $7,764,997$ & $-203,052$ \\
\hline Spain & 690 & 3 & 161,869 & $4,241,011$ & 0 \\
\hline Denmark & 0 & 1 & 32,635 & $6,644,563$ & $-96,571$ \\
\hline France2 & 420,634 & 12 & 254,873 & $10,093,698$ & 358,606 \\
\hline Germany3 & 600,893 & 15 & 515,229 & $17,653,032$ & $-496,551$ \\
\hline TOTAL & $15,117,822$ & 873 & $22,026,284$ & $130,328,117$ & $38,443,066$ \\
\hline minimum & 0 & 0 & 0 & 0 & $-496,551$ \\
\hline maximum & $12,162,944$ & 431 & $15,505,091$ & $44,682,307$ & $36,951,548$ \\
\hline mean & $1,079,844$ & 62 & $1,573,306$ & $9,309,151$ & $2,745,933$ \\
\hline median & 3,350 & 5 & 248,585 & $5,966,684$ & 48,901 \\
\hline
\end{tabular}

The Hungarian subsidiary is a production entity whereas France 2 and Germany 3 are retailers. The other subsidiaries are agencies responsible for the local sellers and work on commission. The Belgian parent company continues to be responsible for billing customers in these countries.

Table 1 presents the collected entity data necessary to apply the AF for the group.

- The factor assets (A) represents the average tax written down value of the fixed tangible assets at the beginning (31/12/2006) and at the end (31/12/2007) of the fiscal year 2007. 
- The combined labour factor consists of both payroll and number of employees. Payroll (P) includes the fiscally accepted costs of workers, employees and directors for the year 2007. This is increased by the fiscally accepted costs of temporary workers and students. The number of employees (E) is calculated as the average number of workers, employees and directors for the fiscal year 2007. The average number of temporary workers and students is added.

- The factor sales (S) consists of sales attributed to each particular entity in 2007, i.e. sales by destination. In case of nowhere sales, the sales are thrown back according to the spread throw back rule.

- Taxable profit represents the individual profit as mentioned in the corporate tax declaration. Taxable group profit (total) equals the sum of taxable profits (according to national rules) of all entities. The group profit takes into account loss compensation but does not eliminate possible intra-group profit.

\subsection{Methodology}

Using the simulation technique, we will evaluate the effects of the number of factors included into the formula as well as the effects of the weights applied to these factors. In order to do this, we form two sets of formulas represented in Table 2. The first set represents 'the factor formulas' that include one, two or three factors when assuming equal weights. We name F3 the classic three factor formula. This is the formula proposed by the Commission. The second set contains 'the weight formulas' applying equal or less equal weights when assuming a three factor formula. Formula Wa uses equal weights, codes starting with $\mathrm{Wb}$ adopt weights of $1 / 2,1 / 4$ and $1 / 4$ whereas codes with $\mathrm{Wc}$ apply even more unequal weights, namely $2 / 3,1 / 6$ and $1 / 6$. We choose weights that are in line with realistic weights of AF in the US. (Weiner 2005). Also, the Commission is interested in simulations using these weights (EC 2007c).

For each entity the different formulas result in an entity share (ES) and in an entity percentage payable (EPP). An ES is the share an entity gets of the common tax base when a specific formula is applied. The EPP on the common tax base is the product of its ES and the corporate tax rate (CTR) applied in its country:

$$
\mathrm{EPP}_{i}=\mathrm{ES}_{i}{ }^{*} \mathrm{CTR}_{i} \text {. }
$$

Adding these $\mathrm{EPP}_{i}$ results in the global corporate tax rate for the group (GCTR):

$$
\mathrm{GCTR}=\sum_{i=1}^{n}\left(\mathrm{ES}_{i} * \mathrm{CTR}_{i}\right)
$$

where subscript $i$ denotes entity $i$ from a group of $n$ entities.

Finally, we look at the allocation effects of using simplified factor definitions instead of the more complex factor definitions as proposed by the Commission. To study these allocation effects we first look at the impact of simplifying one factor while keeping the others constant. Afterwards, we consider the allocation impact of including all three simplified factors. We simplify assets by using the book value of fixed tangible assets on the 31th of December 2007 instead of the average of the tax written down value at the beginning (31th December 2006) and ending of the tax year (31th December 2007). 
Table 2. Factor and weight formulas

\begin{tabular}{|c|c|c|c|}
\hline & Factor Formulas & & Weight Formulas \\
\hline F1a & $\mathrm{ES}_{i}=\frac{\mathrm{S}_{i}}{\mathrm{~S}}$ & Wa & $\mathrm{ES}_{i}=\frac{1}{3} \frac{\mathrm{S}_{i}}{\mathrm{~S}}+\frac{1}{3}\left[\frac{1}{2} \frac{\mathrm{P}_{i}}{\mathrm{P}}+\frac{1}{2} \frac{\mathrm{E}_{i}}{\mathrm{E}}\right]+\frac{1}{3} \frac{\mathrm{A}_{i}}{\mathrm{~A}}$ \\
\hline F1b & $\mathrm{ES}_{i}=\frac{1}{2} \frac{\mathrm{P}_{i}}{\mathrm{P}}+\frac{1}{2} \frac{\mathrm{E}_{i}}{\mathrm{E}}$ & $\mathrm{Wb} 0$ & $\mathrm{ES}_{i}=\frac{1}{2} \frac{\mathrm{S}_{i}}{\mathrm{~S}}+\frac{1}{4}\left[\frac{1}{2} \frac{\mathrm{P}_{i}}{\mathrm{P}}+\frac{1}{2} \frac{\mathrm{E}_{i}}{\mathrm{E}}\right]+\frac{1}{4} \frac{\mathrm{A}_{i}}{\mathrm{~A}}$ \\
\hline F1c & $\mathrm{ES}_{i}=\frac{\mathrm{A}_{i}}{\mathrm{~A}}$ & Wb1c & $\mathrm{ES}_{i}=\frac{1}{4} \frac{\mathrm{S}_{i}}{\mathrm{~S}}+\frac{1}{2}\left[\frac{1}{2} \frac{\mathrm{P}_{i}}{\mathrm{P}}+\frac{1}{2} \frac{\mathrm{E}_{i}}{\mathrm{E}}\right]+\frac{1}{4} \frac{\mathrm{A}_{i}}{\mathrm{~A}}$ \\
\hline $\mathrm{F} 2 \mathrm{a}$ & $\mathrm{ES}_{i}=\frac{1}{2} \frac{\mathrm{S}_{i}}{\mathrm{~S}}+\frac{1}{2}\left[\frac{1}{2} \frac{\mathrm{P}_{i}}{\mathrm{P}}+\frac{1}{2} \frac{\mathrm{E}_{i}}{\mathrm{E}}\right]$ & $\mathrm{Wb} 2$ & $\mathrm{ES}_{i}=\frac{1}{4} \frac{\mathrm{S}_{i}}{\mathrm{~S}}+\frac{1}{4}\left[\frac{1}{2} \frac{\mathrm{P}_{i}}{\mathrm{P}}+\frac{1}{2} \frac{\mathrm{E}_{i}}{\mathrm{E}}\right]+\frac{1}{2} \frac{\mathrm{A}_{i}}{\mathrm{~A}}$ \\
\hline $\mathrm{F} 2 \mathrm{~b}$ & $\mathrm{ES}_{i}=\frac{1}{2} \frac{\mathrm{S}_{i}}{\mathrm{~S}}+\frac{1}{2} \frac{\mathrm{A}_{i}}{\mathrm{~A}}$ & $\mathrm{Wc} 0$ & $\mathrm{ES}_{i}=\frac{2}{3} \frac{\mathrm{S}_{i}}{\mathrm{~S}}+\frac{1}{6}\left[\frac{1}{2} \frac{\mathrm{P}_{i}}{\mathrm{P}}+\frac{1}{2} \frac{\mathrm{E}_{i}}{\mathrm{E}}\right]+\frac{1}{6} \frac{\mathrm{A}_{i}}{\mathrm{~A}}$ \\
\hline $\mathrm{F} 2 \mathrm{c}$ & $\mathrm{ES}_{i}=\frac{1}{2} \frac{\mathrm{A}_{i}}{\mathrm{~A}}+\frac{1}{2}\left[\frac{1}{2} \frac{\mathrm{P}_{i}}{\mathrm{P}}+\frac{1}{2} \frac{\mathrm{E}_{i}}{\mathrm{E}}\right]$ & Wc1 & $\mathrm{ES}_{i}=\frac{1}{6} \frac{\mathrm{S}_{i}}{\mathrm{~S}}+\frac{2}{3}\left[\frac{1}{2} \frac{\mathrm{P}_{i}}{\mathrm{P}}+\frac{1}{2} \frac{\mathrm{E}_{i}}{\mathrm{E}}\right]+\frac{1}{6} \frac{\mathrm{A}_{i}}{\mathrm{~A}}$ \\
\hline F3 & $\mathrm{ES}_{i}=\frac{1}{2} \frac{\mathrm{S}_{i}}{\mathrm{~S}}+\frac{1}{3}\left[\frac{1}{2} \frac{\mathrm{P}_{i}}{\mathrm{P}}+\frac{1}{2} \frac{\mathrm{E}_{i}}{\mathrm{E}}\right]+\frac{1}{3} \frac{\mathrm{A}_{i}}{\mathrm{~A}}$ & $\mathrm{Wc} 2$ & $\mathrm{ES}_{i}=\frac{1}{6} \frac{\mathrm{S}_{i}}{\mathrm{~S}}+\frac{1}{6}\left[\frac{1}{2} \frac{\mathrm{P}_{i}}{\mathrm{P}}+\frac{1}{2} \frac{\mathrm{E}_{i}}{\mathrm{E}}\right]+\frac{2}{3} \frac{\mathrm{A}_{i}}{\mathrm{~A}}$ \\
\hline
\end{tabular}

We simplify the combined labour factor by defining the work force as the average number of workers, employees and directors in 2007 and their payroll costs as the costs mentioned in the profit and loss accounts 2007. According to the European proposal the work force should also include temporary workers and students and payroll cost should be the fiscally accepted costs. With respect to the sales by destination factor we take into account a pure throw back rule instead of the proposed spread throw back rule. A pure throw back rule implies that all sales that are going to a European country where the group lacks a taxing nexus or to a non-European country (i.e. 'nowhere' sales), are thrown back to the state of origin. By contrast, a spread throw back rule assigns these sales to all group entities in proportion to the other formula factors.

\section{Results and discussion}

\subsection{Varying the number of factors}

Table 3 contains the ES each entity gets from the common tax base when simulating the different factor formulas (Panel A). The table also contains the EPP on the common tax base as well as the GCTR of the group when simulating these factor formulas (Panel B).

From Panel B we can see that the group has the lowest GCTR when applying the formula only including the combined labour factor (F1b). Under these circumstances, the GCTR equals $30.09 \%$. This favourable result can be explained by the fact that the 


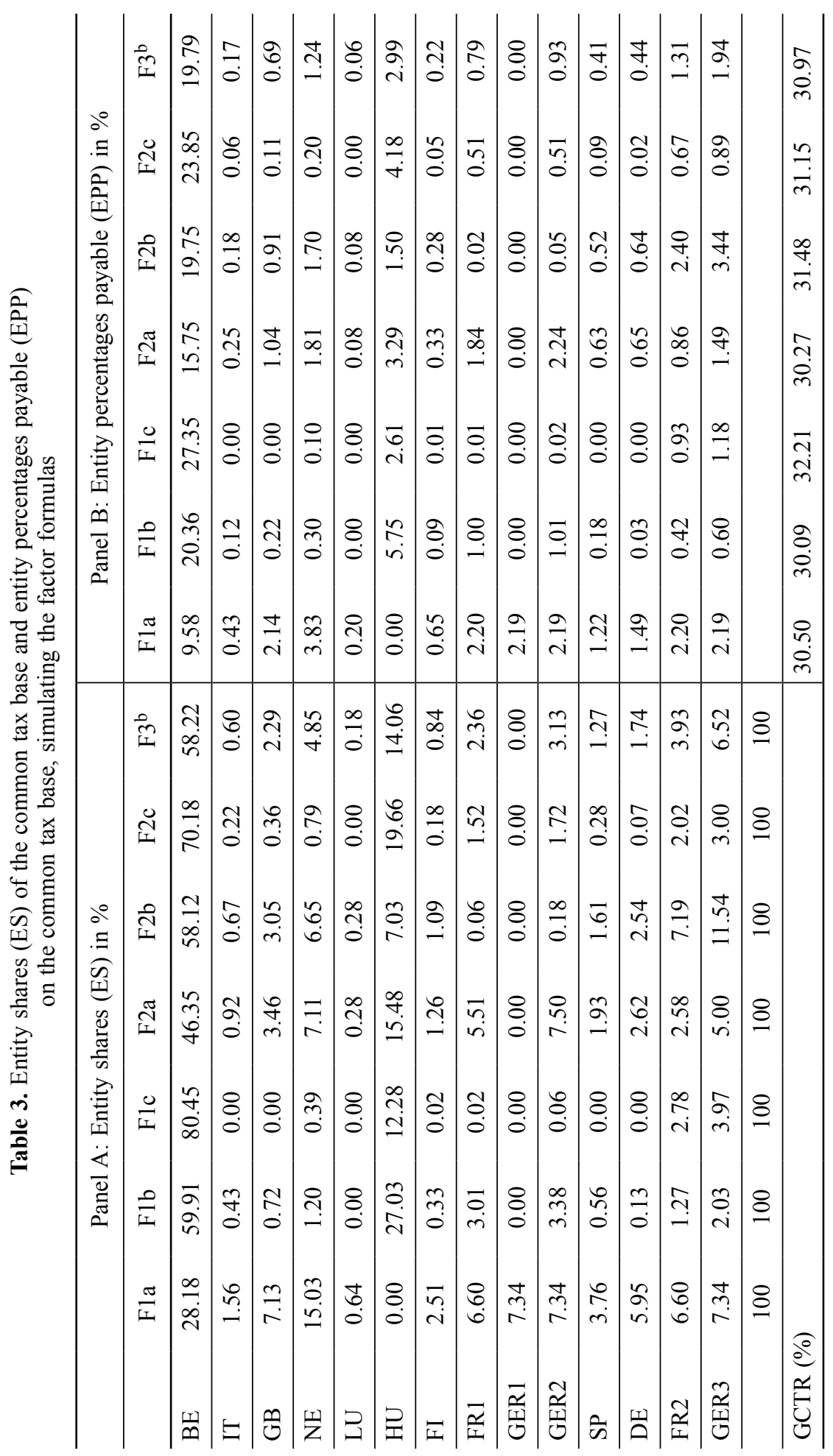


combined labour factor is abundantly present in Hungary, the country with the lowest tax rate of the group. When we have a look at Panel A, formula F1b apportions 27.03\% of the common tax base to Hungary, which is the highest ES of all ES going to Hungary.

Panel A also illustrates that the more factors included into the formula, the more chance the Belgian group would get an equally distributed common tax base. For the one-factor formulas (F1), the minimum and maximum share an entity can get from the common tax base is $0 \%$ and $80.45 \%$ respectively. The two-factor formulas (F2) apportion a minimum of $0 \%$ and a maximum of $70.18 \%$ to an entity, while the three-factor formula finds a minimum of $0 \%$ and a maximum of $58.22 \%$. We can see that the spread between the minimum and the maximum shares an entity can get becomes smaller as more factors are included.

The distribution of the common tax base is also visualised in Figure 1. This figure represents a graph which uses the concept of a Lorenz curve applied to the distribution of the common tax base among entities. All entities are arranged from smallest to largest concerning their ES of the common tax base. Afterwards, these shares are cumulated. The results show that the more factors included into the formula, the more the distribution of the common tax base approaches an equal distribution.

A more equally distributed common tax base, as a result of including more factors into the formula, could reduce the incentive to shift one or more allocation factor(s). The relocation of one unit of these factors would shift less than one unit of the common tax base. In order to illustrate this, we assume the extreme case where the Belgian group would shift all Belgian fixed tangible assets to its entity located in the low tax country Hungary. Table 4 represents the distribution of the common tax base before and after shifting. Our starting point are the figures of the tax year 2007 from Table 1. This table shows that the Belgian entity has an amount of $€ 12,162,944$ fixed tangible assets which equals $80.45 \%$ of the total amount. For the one factor formula including assets (F1c), the relocation of this $80.45 \%$ from the Belgian entity to the Hungarian entity effectively shifts $80.45 \%$ (92.74-12.28\%) of the common tax base to the Hungarian entity. Look-

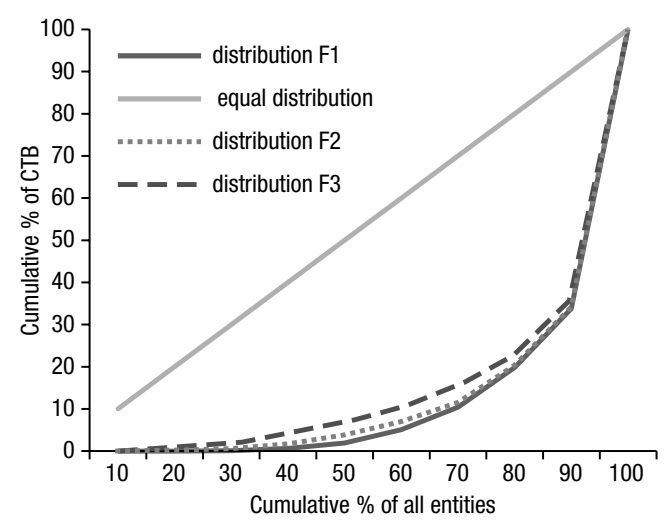

Fig. 1. Distribution of the CTB resulting from the one, two and three factor formula 
ing at the two factor formulas including assets (F2b and F2c), the relocation of $80.45 \%$ of total assets only shifts $46.08 \%(53.11-7.03 \%)$ and $40.23 \%(59.89-19.66 \%)$ of the common tax base to the Hungarian entity. For the three factor formula the distribution effect is the smallest, namely the relocation only shifts $28.77 \%(42.83-14.06 \%)$ of the common tax base to the Hungarian entity. When shifting labour or sales from a high tax country to a low tax country, similar results could be found. In brief, our example illustrates that the incentive to shift an allocation factor could be reduced by including more factors into the formula.

Table 4. ES of the common tax base before and after shifting (factor formulas including assets)

\begin{tabular}{lcccc|cccc}
\hline \multicolumn{3}{c}{ ES before shifting (tax year 2007) in $\%$} & \multicolumn{4}{c}{ ES after shifting in $\%$} \\
\hline & F1c & F2b & F2c & F3 & F1c & F2b & F2c & F3 \\
\hline BE & 80.45 & 58.12 & 70.18 & 58.22 & 0.00 & 12.04 & 29.95 & 29.45 \\
\hline IT & 0.00 & 0.67 & 0.22 & 0.60 & 0.00 & 0.67 & 0.22 & 0.60 \\
\hline GB & 0.00 & 3.05 & 0.36 & 2.29 & 0.00 & 3.05 & 0.36 & 2.29 \\
\hline NE & 0.39 & 6.65 & 0.79 & 4.85 & 0.39 & 6.65 & 0.79 & 4.85 \\
\hline LU & 0.00 & 0.28 & 0.00 & 0.18 & 0.00 & 0.28 & 0.00 & 0.18 \\
\hline HU & 12.28 & 7.03 & 19.66 & 14.06 & 92.74 & 53.11 & 59.89 & 42.83 \\
\hline FI & 0.02 & 1.09 & 0.18 & 0.84 & 0.02 & 1.09 & 0.18 & 0.84 \\
\hline FR1 & 0.02 & 0.06 & 1.52 & 2.36 & 0.02 & 0.06 & 1.52 & 2.36 \\
\hline GER1 & 0.00 & 0.00 & 0.00 & 0.00 & 0.00 & 0.00 & 0.00 & 0.00 \\
\hline GER2 & 0.06 & 0.18 & 1.72 & 3.13 & 0.06 & 0.18 & 1.72 & 3.13 \\
\hline SP & 0.00 & 1.61 & 0.28 & 1.27 & 0.00 & 1.61 & 0.28 & 1.27 \\
\hline DE & 0.00 & 2.54 & 0.07 & 1.74 & 0.00 & 2.54 & 0.07 & 1.74 \\
\hline FR2 & 2.78 & 7.19 & 2.02 & 3.93 & 2.78 & 7.19 & 2.02 & 3.93 \\
\hline GER3 & 3.97 & 11.54 & 3.00 & 6.52 & 3.97 & 11.54 & 3.00 & 6.52 \\
\hline & 100 & 100 & 100 & 100 & 100 & 100 & 100 & 100 \\
\hline
\end{tabular}

\subsection{Varying the factor weights}

Table 5 contains the ES (Panel A) and the EPP (Panel B) when simulating the weight formulas. From Panel B we can see that the group has the lowest GCTR when applying the formula putting the largest weight $(2 / 3)$ on the combined labour factor (Wc1). Under these circumstances the GCTR equals $30.53 \%$. This favourable result can again be explained by the fact that the combined labour factor is abundantly present in Hungary. When we have a look at Panel A, formula Wc1 apportions $20.55 \%$ of the common tax base to Hungary, which is the highest ES of all ES going to Hungary. 


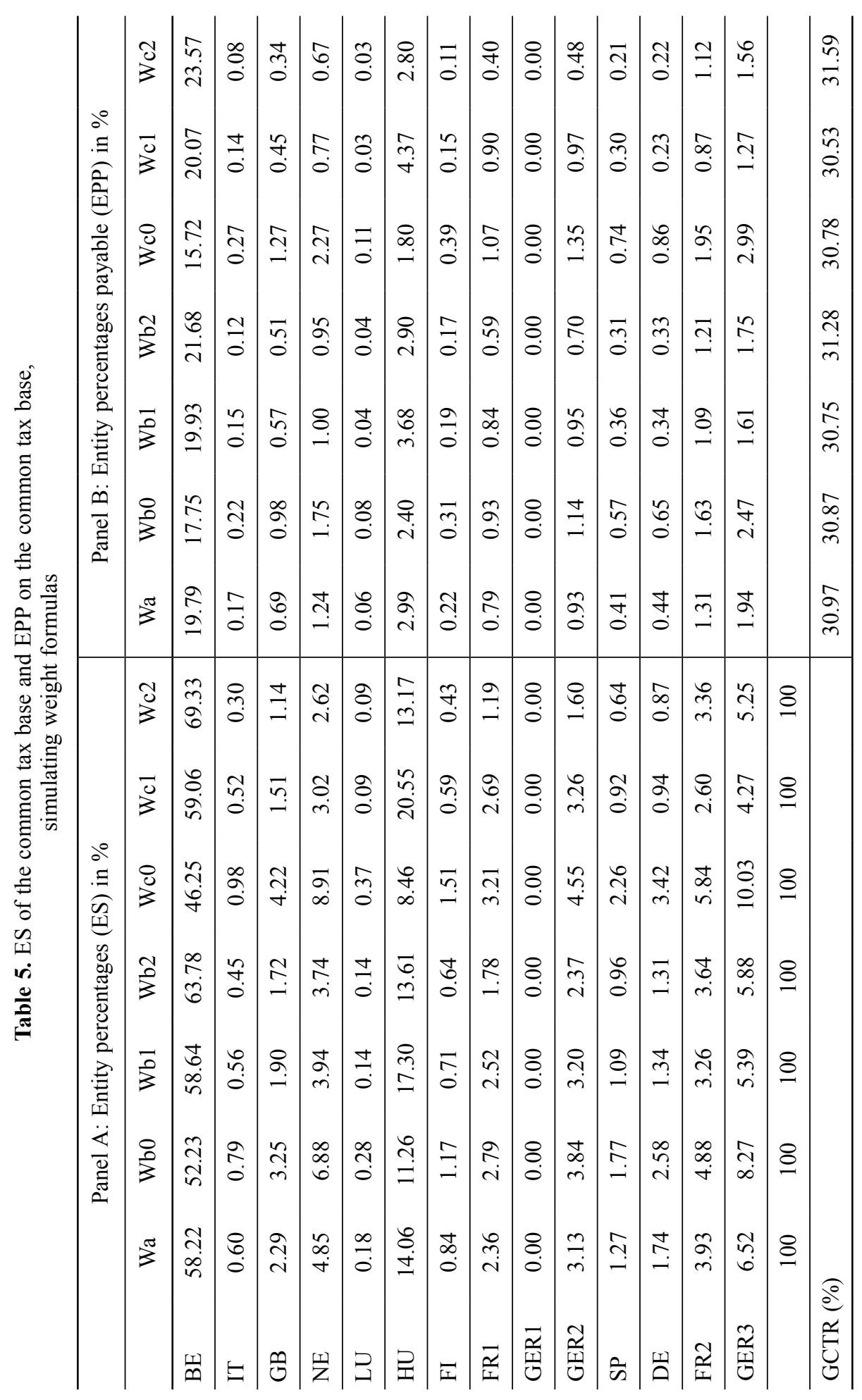


Panel A also illustrates that the more equal the weights are, the more chance the Belgian group would get an equally distributed common tax base. When applying the most unequal weights ( $\mathrm{Wc} 0, \mathrm{Wc} 1, \mathrm{Wc} 2)$, the minimum apportionment share an entity can get is $0 \%$ and the maximum share $69.33 \%$. Less unequal weights ( $\mathrm{Wb} 0, \mathrm{~Wb} 1, \mathrm{~Wb} 2)$ result in a minimum share of $0 \%$ and a maximum share of $63.78 \%$. The equally weighted three factor formula (Wa) leads to a minimum of $0 \%$ and a maximum of $58.22 \%$. We can see that the spread between the minimum and maximum shares an entity can get becomes smaller when applying more equal weights. This can also be visualized by Lorenz curves which can be given upon request.

A more equally distributed common tax base, as a result of applying more equal weights to the factors, could reduce the incentive to shift one or more allocation factor(s). In order to illustrate this, we follow the same procedure as explained under 'varying the number of factors'. The results can be given upon request.

\subsection{Varying the factor definitions}

Table 6 gives the ES and the GCTR when using more easily defined factor definitions. These results concern simplifications of the classic three factor formula. We first look at the impact of simplifying one factor while keeping the others constant. Table 6 shows that simplifying the factor definition of assets (ii) results in a maximum entity change in the allocation of the common tax base of only $2.93 \%$ (FR2). Using a more easy combined labour factor (iii) leads to a maximum change of only $1.14 \%$ (HU). Applying the pure throw back rule in order to simplify the sales by destination factor (iv) results in a maximum change of $37.20 \%$ (GER3). On the group level, simplifying assets leads to rather minor changes into the GCTR (relative change of $0.03 \%$ ). The same conclusion can be made when simplifying the combined labour factor (relative change of $0.07 \%$ ). Applying the pure throw back rule results in a somewhat higher change into the GCTR (relative change of $0.44 \%$ ). Secondly, we look at the allocation effects when including all three simplified factors (v). In this case, the entity change is limited to $38.55 \%$ (GER3) and the relative change in the GCTR equals $0.4 \%$.

We cannot generalize these results because of the particularity of each case. However, these results indicate that it would be interesting to study the average effect on a large scale sample. If using simplified factor definitions on average leads to rather minor changes in the allocation of the common tax base, it could be appropriate to investigate whether or not the higher compliance costs the proposed definitions bring along are justified.

Finally, we would like to mention that especially applying the spread throw back rule is a complex matter. However, using a less complex pure throw back rule instead of the spread throw back rule transforms the sales by destination factor into a more originbased factor and as a consequence disturbs the balance between the supply and demand side of profit generating factors. This also re-introduces tax planning opportunities to manipulate the starting points of exports. Keeping this in mind, it is desirable to apply a spread throw back rule to nowhere sales. In order to solve the remaining problem of complexity, it could be helpful to reach multinational groups a computer-based tool that enables them to apply the spread throw back rule without great efforts. 
Table 6. ES of the common tax base and the global corporate tax rates

(GCTR) using simplified factors

Factor definitions formula F3

(i) non simplified assets, combined labour and sales by destination

(ii) simplified assets

(iii) simplified combined labour

(iv) simplified sales by destination

(v) simplified assets, combined labour and sales by destination

\begin{tabular}{|c|c|c|c|c|c|c|}
\hline & & (i) & (ii) & (iii) & (iv) & (v) \\
\hline \multirow[t]{2}{*}{$\mathrm{BE}$} & ES (\%) & 58.22 & 58.45 & 58.01 & 59.66 & 59.68 \\
\hline & $\%$ change & & 0.40 & -0.36 & 2.48 & 2.52 \\
\hline \multirow[t]{2}{*}{ IT } & ES (\%) & 0.60 & 0.60 & 0.60 & 0.59 & 0.59 \\
\hline & $\%$ change & & -0.01 & 0.20 & -1.75 & -1.58 \\
\hline \multirow[t]{2}{*}{ GB } & ES (\%) & 2.29 & 2.29 & 2.29 & 2.27 & 2.27 \\
\hline & \% change & & 0.00 & 0.10 & -0.76 & -0.67 \\
\hline \multirow[t]{2}{*}{$\mathrm{NE}$} & ES (\%) & 4.85 & 4.90 & 4.85 & 4.81 & 4.86 \\
\hline & $\%$ change & & 0.99 & 0.09 & -0.79 & 0.21 \\
\hline \multirow[t]{2}{*}{ LU } & ES (\%) & 0.18 & 0.18 & 0.18 & 0.18 & 0.18 \\
\hline & \% change & & 0.00 & 0.00 & 0.00 & 0.00 \\
\hline \multirow[t]{2}{*}{$\mathrm{HU}$} & ES (\%) & 14.06 & 14.00 & 14.22 & 13.11 & 13.20 \\
\hline & \% change & & -0.40 & 1.14 & -6.78 & -6.09 \\
\hline \multirow[t]{2}{*}{ FI } & ES (\%) & 0.84 & 0.84 & 0.84 & 0.83 & 0.83 \\
\hline & $\%$ change & & -0.12 & 0.15 & -1.01 & -0.98 \\
\hline \multirow[t]{2}{*}{ FR1 } & ES (\%) & 2.36 & 2.36 & 2.37 & 2.89 & 2.90 \\
\hline & $\%$ change & & -0.05 & 0.45 & 22.37 & 22.75 \\
\hline \multirow[t]{2}{*}{ GER1 } & ES (\%) & 0.00 & 0.00 & 0.00 & 2.09 & 2.09 \\
\hline & $\%$ change & & $(i i-i) / 0$ & $(i i i-i) / 0$ & $(i v-i) / 0$ & $(v-i) / 0$ \\
\hline \multirow[t]{2}{*}{ GER2 } & ES (\%) & 3.13 & 3.13 & 3.14 & 3.24 & 3.25 \\
\hline & $\%$ change & & -0.12 & 0.36 & 3.34 & 3.61 \\
\hline \multirow[t]{2}{*}{ SP } & ES (\%) & 1.27 & 1.27 & 1.27 & 1.26 & 1.26 \\
\hline & $\%$ change & & 0.00 & 0.17 & -1.07 & -0.92 \\
\hline \multirow[t]{2}{*}{$\mathrm{DE}$} & $\mathrm{ES}$ & 1.74 & 1.74 & 1.74 & 1.74 & 1.74 \\
\hline & $\%$ change & & 0.00 & 0.03 & -0.18 & -0.15 \\
\hline \multirow[t]{2}{*}{ FR2 } & ES (\%) & 3.93 & 3.82 & 3.94 & 3.23 & 3.13 \\
\hline & $\%$ change & & -2.93 & 0.15 & -17.81 & -20.40 \\
\hline \multirow[t]{2}{*}{ GER3 } & ES (\%) & 6.52 & 6.42 & 6.52 & 4.09 & 4.00 \\
\hline & \% change & & -1.55 & 0.13 & -37.20 & -38.55 \\
\hline \multirow[t]{2}{*}{ GCTR (\%) } & & 30.97 & 30.97 & 30.94 & 31.10 & 31.09 \\
\hline & $\%$ change & & 0.03 & -0.07 & 0.44 & 0.40 \\
\hline
\end{tabular}




\section{Conclusion}

The European Commission (EC) has the intention to establish a Common Consolidated Corporate Tax Base (CCCTB) in order to increase the efficiency, effectiveness, simplicity and transparency of the European company tax system. This study uses firm level data from a listed multinational in order to assess how several designs of the CCCTB formula could affect the allocation of the consolidated tax base. We investigate to what extent the allocation effects differ when including one or more factor(s) into the formula or putting high or low weights on the formula factors. Moreover, we study how the design of the apportionment formula is related to the intention to shift formula factors. Further, we examine the allocation effects of using simplified factor definitions instead of the more complex factor definitions as proposed by the Commission.

The simulation results show that the design of the apportionment formula is important in affecting the distribution of the common tax base. Specifically, including more factors and using more equal weights distributes the common tax base more equally, which could reduce the group's incentive to shift factors from high to low tax countries. These results suggest that in order to create an efficient formula, i.e. a formula not causing any behavioural distortions, more factors should be included. Also, applying more equal weights to the factors could contribute to this aim. The results also indicate that simplifying the factor definitions as proposed by the Commission, leads to rather minor changes in the allocation of the common tax base. However, we are not big proponents of simplifying the sales by destination factor. Simplifying this sales factor, by applying the pure throw back rule instead of the spread throw back rule, transforms the factor into a more origin based factor. Therefore, we suggest the Commission to reach multinational groups a computer-based tool enabling them to apply the spread throw back rule without great efforts.

\section{References}

Agundez-Garcia, A. 2006. The delineation and apportionment of an EU consolidated tax base for multi-jurisdictional corporate income taxation: a review of issues and options, Working paper No 9. European Commission Taxation Papers.

Anand, B.; Sansing, R. 2000. The weighting game: formula apportionment as an instrument of public policy, National Tax Journal 53(2): 183-199.

Bettendorf, L.; Devereux, M. P.; van der Horst, A.; Loretz, S.; de Mooij, R. A. 2010. Corporate tax harmonization in the EU, Economic Policy 63: 537-590.

http://dx.doi.org/10.1111/j.1468-0327.2010.00248.x

Devereux, M. P.; Loretz, S. 2008. The effects of EU formula apportionment on corporate tax revenues, Fiscal Studies 29(1): 1-33. http://dx.doi.org/10.1111/j.1475-5890.2008.00067.x

European Commission (EC). 2001a. Towards an internal market without tax obstacles, Working paper $\{\mathrm{COM}(2001) 582$ final $\}$. Brussels.

European Commission (EC). 2001b. Company taxation in the internal market, Working paper $\{\mathrm{COM}(2001) 582$ final $\}$. Brussels.

European Commission (EC). 2006a. Issues related to group taxation, Working paper (CCCTB $\mathrm{WP} \backslash 035 \backslash$ doclen). Brussels. 
European Commission (EC). 2006b. The mechanism for sharing the CCCTB, Working paper (CCCTB $\backslash W P \backslash 047 \backslash$ doclen). Brussels.

European Commission (EC). 2007a. Possible elements of a technical outline, Working paper (CCCTB $\backslash W P 057 \backslash$ doclen). Brussels.

European Commission (EC). 2007b. Possible elements of the sharing mechanism, Working paper (CCCTB $\backslash W P 060 \backslash$ doclen). Brussels.

European Commission (EC). 2007c. Input from national tax administrations for the impact assessment of the reforms at the EU level of corporate tax systems, Working paper (CCCTB WP058\doclen). Brussels.

European Commission (EC). 2010. Europe 2020: a strategy for smart, sustainable and inclusive growth. Working paper $\{\mathrm{COM}(2010) 2020\}$. Brussels.

European Commission (EC). 2011a. Taxes in Europe: Database (referred on 19/01/2011).

Ginevicius, R. 2010. The effectiveness of cooperation of industrial enterprises, Journal of Business Economics and Management 11(2): 283-296. http://dx.doi.org/10.3846/jbem.2010.14

Hellerstein, W. 2005. The case for formulary apportionment, International Transfer Pricing Journal 3: 103-111.

Hey, J. 2008. EU common consolidated corporate tax base: guided variety versus strict uniformity, Jean Monnet Working paper 02/08. New York University School of Law.

Runkel, M.; Schjelderup, G. 2011. The choice of apportionment factors under formula apportionment, International Economic Review 52(3): 913-934.

http://dx.doi.org/10.1111/j.1468-2354.2011.00654.x

Schön, W.; Screiber, U.; Spengel, C. 2008. A Common Consolidated Corporate Tax Base for Europe. Berlin, Heidelberg: Springer.

Spengel, C.; Wendt, C. 2007. A common consolidated corporate tax base for multinational companies in the European Union: some issues and options, Working Paper WP 07\17. Oxford University Centre for Business Taxation.

Weiner, J. M. 2005. Formulary apportionment and group taxation in the European Union: insights from the United States and Canada, Working paper No 8. European Commission Taxation Papers.

Annelies ROGGEMAN is a PhD student at the University College Ghent/Ghent University, where she carries out research concerning the evaluation of the Common Consolidated Corporate Tax Base. She graduated in 2004 as a Master in Commercial Engineering.

Isabelle VERLEYEN is a PhD student at the University College Ghent/Ghent University, where she carries out research concerning the evaluation of the Common Consolidated Corporate Tax Base. She graduated in 2008 as a Master of Business Economics.

Philippe VAN CAUWENBERGE is a Professor at the Department of Accountancy and Corporate Finance of the Ghent University, where he teaches courses in financial analysis, IFRS and Research Methods. His research has been published in journals like Public Choice, Abacus and Public Money and Management.

Carine COPPENS is the head of the Department of Financial Management at the University College Ghent, Faculty of Business and Information Management. She is coordinator of the program applied taxation. As a researcher in the field of corporate taxation, she is affiliated with the Ghent University, Department of Accountancy and Corporate Finance. 